


\title{
DIE EXPLOSIVSTOFFE
}

MIT BESONDERER BERÜCKSICHTIGUNG

\section{DER NEUEREN PATENTE}

\author{
BEARBEITET \\ VON \\ DR. RICHARD ESCALES
}

SIEBENTES HEFT

INITIALEXPLOSIVSTOFFE

LEIPZIG

VERLAG VON VEIT \& COMP. 


\title{
INITIALEXPLOSIVSTOFFE
}

\author{
VON \\ DR. RICHARD ESCALES \\ UND \\ DR. ALFRED STETTBACHER
}

MIT ZAHLREICHEN FIGUREN

LEIPZIG

VERLAG VON VEIT \& COMP.

1917 
Druck von Metzger \& Wittig in Leipzig. 